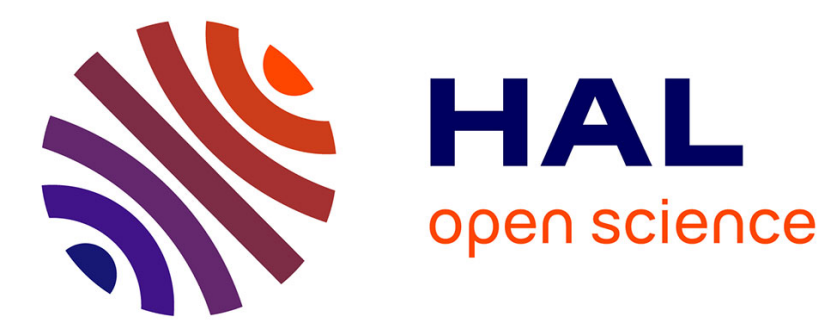

\title{
Distinct discharge modes in micro Hall thruster plasmas
}

Dongho Lee, Guentae Doh, Holak Kim, Laurent Garrigues, Wonho Choe

\section{To cite this version:}

Dongho Lee, Guentae Doh, Holak Kim, Laurent Garrigues, Wonho Choe. Distinct discharge modes in micro Hall thruster plasmas. Plasma Sources Science and Technology, 2021, 30 (3), pp.035004. 10.1088/1361-6595/abdf19 . hal-03212999

\section{HAL Id: hal-03212999 \\ https://hal.science/hal-03212999}

Submitted on 30 Apr 2021

HAL is a multi-disciplinary open access archive for the deposit and dissemination of scientific research documents, whether they are published or not. The documents may come from teaching and research institutions in France or abroad, or from public or private research centers.
L'archive ouverte pluridisciplinaire $\mathbf{H A L}$, est destinée au dépôt et à la diffusion de documents scientifiques de niveau recherche, publiés ou non, émanant des établissements d'enseignement et de recherche français ou étrangers, des laboratoires publics ou privés. 


\title{
Distinct discharge modes in micro Hall thruster plasmas
}

\author{
Dongho Lee ${ }^{1}$, Guentae Doh ${ }^{1}$, Holak Kim ${ }^{2}$, Laurent Garrigues ${ }^{3}$ and Wonho Choe ${ }^{1,4, *}$ \\ ${ }^{1}$ Department of Physics, Korea Advanced Institute of Science and Technology (KAIST), 291 Daehak-ro, \\ Yuseong-gu, Daejeon 34141, Republic of Korea \\ ${ }^{2}$ Satellite Research Directorate, Korea Aerospace Research Institute (KARI), 169-84 Gwahak-ro, Yuseong-gu, \\ Daejeon 34133, Republic of Korea \\ ${ }^{3}$ LAPLACE, Université de Toulouse, CNRS, F-31062 Toulouse, France \\ ${ }^{4}$ Department of Nuclear and Quantum Engineering, Korea Advanced Institute of Science and Technology \\ (KAIST), 291 Daehak-ro, Yuseong-gu, Daejeon 34141, Republic of Korea
}

Author to whom correspondence should be addressed; E-mail: wchoe@kaist.ac.kr

\begin{abstract}
Two distinct discharge modes were observed in a 50-W-class micro-Hall thruster plasma under different operating conditions. A ball-shaped plasma with a broad plume (Mode A) was observed at low mass flow rates (less than 0.37 $\mathrm{mg} / \mathrm{s})$ over the entire operational anode voltage range $(160-280 \mathrm{~V})$. Raising the anode voltage beyond $200 \mathrm{~V}$ with the mass flow rate fixed (larger than $0.37 \mathrm{mg} / \mathrm{s}$ ) produced a narrow plume and stretched core structure (Mode B). In Mode B, the thruster showed performance improvements in terms of thrust ( $3.8 \mathrm{mN}$ vs. $3.3 \mathrm{mN}$ ), specific impulse (913 s vs. $800 \mathrm{~s}$ ), and anode efficiency ( $28 \%$ vs. $22 \%$ ), with only a $2 \mathrm{~W}$ difference in the anode power (61 W in Mode B and $59 \mathrm{~W}$ in Mode A). This suggests that operation is more advantageous in Mode B than in Mode A for the utilization of such low-power Hall thrusters. A considerable difference was observed in the axial profile of Xe II ion velocity between the two modes. Mode A exhibits an axially extended ion acceleration region outside the discharge channel, where $75 \%$ of the final ion velocity is achieved at approximately $40 \mathrm{~mm}$ from the thruster exit, while most of the ion acceleration occurs within $10 \mathrm{~mm}$ from the thruster exit in Mode B. Measurements show that the full width at half maximum of the Xe II ion energy distribution function, electron temperature, and Xe II emission intensity decreased after the plasma transitioned from Mode A to Mode B. Based on the optical emission spectroscopy, the ionization rate in the plasma plume decreased by $30-41 \%$ after the mode change, which is likely related to the reduction of the beam angle and electron current by $24 \%$ and $30 \%$, respectively.
\end{abstract}

Keywords: Low-power Hall thrusters, magnetic field tailoring, mode change, ionization region 


\section{Introduction}

Due to their high specific impulse and thrust-to-power ratio [1,2], Hall thrusters have played key roles in a wide variety of space missions, including providing fine control of a spacecraft's attitude or altitude, thrust for orbit transfers, and propulsion for deep space missions $[3,4]$. Recently, advancements in micro-electronic technologies have enabled the development of affordable miniaturized satellites with masses near or below $100 \mathrm{~kg}$. This has led to a rapid increase in the demand for these satellites, particularly for low-earth-orbit missions [5]. In order to effectively utilize this class of satellite and spacecraft, it has become increasingly important to develop highperformance Hall thrusters, which can operate at $100 \mathrm{~W}$ or below.

However, the development of low-power Hall thrusters is associated with several scientific and technical difficulties that are mainly related to the reduction of the size of the discharge channel and the optimization of the corresponding magnetic field. In low-power Hall thrusters, the particle and power losses to the channel wall inevitably increase due to the large surface-to-volume ratio of the plasma, which can ultimately result in the degradation of the thruster performance [6]. Previous studies report that the thrusters near or below $100 \mathrm{~W}$ exhibit lower thruster efficiency compared to their higher power counterparts $[7,8,10]$. The thrust performance has been shown to degrade further at lower power, particularly when operating near $50 \mathrm{~W}$ [9-13].

In general, the structure of the ionization region or the spatial profile of the ionization rate in the Hall thruster plasma depends on various plasma parameters, including the electron temperature and energy distribution, and is also highly related to the profile of the electrostatic potential. This ultimately has an influence on the global thruster performance. Compared with high power kW-class Hall thrusters, 100-W-class Hall thrusters typically have high ratios of channel width to mean diameter to prevent the surface-to-volume ratio of the plasma from dramatically increasing at small channel diameters [14]. Therefore, these 100-W-class Hall thrusters typically have a limited inner pole diameter and inevitably a strong magnetic field adjacent to the inner pole surface and channel exit, particularly when using permanent magnets. Additionally, these micro-Hall thrusters generally require a higher propellant mass flow rate per channel volume $(\dot{m} / V)$ where $\dot{m}$ and $V$ are the mass flow rate for nominal operation and the total volume of the discharge channel, respectively. Hall thrusters operating at $300 \mathrm{~W}$ or less require $0.20-0.62 \mathrm{mg} / \mathrm{cm}^{3} \cdot \mathrm{s}[15,16]$, which is much larger than in $\mathrm{kW}$-class Hall thrusters $\left(0.07-0.19 \mathrm{mg} / \mathrm{cm}^{3} \cdot \mathrm{s}\right)$ $[17,18]$. Thus, it is expected that the strong magnetic field and large neutral particle supply per unit volume in lowpower Hall thrusters affect the electron mobility as well as the ionization in the near-plume region, which can exhibit a different ionization rate profile compared to that of $\mathrm{kW}$-class Hall thrusters. Our study investigates the structure of the ionization region and its correlation with ion acceleration under various operational conditions in low-power Hall thruster plasmas.

In this study, we demonstrate the presence of two discharge modes observed in a 50-W-class Hall thruster plasma. The improvements in the performance, observed when the discharge mode was changed, were analyzed using various diagnostic results. The correlation between the structure of the ionization and acceleration regions and the thruster performance in each mode is discussed in relation to the measured properties of the plasma plume.

\section{Experimental Setup}

The thruster used in this study was a 50-W-class Hall thruster, whose channel structure and magnetic field lines are depicted in Fig. 1. Its magnetic field, generated by a combination of a permanent magnet and an electromagnet, grazes the chamfered channel wall and forms a convex shape oriented towards the anode [19]. The maximum radial magnetic field strength is located at $0.95 \mathrm{~L}$ from the anode surface along the mid-channel line, where $\mathrm{L}$ is the channel depth. The thruster was mounted on a movable $x-y$ stage, with a travel length of $100 \mathrm{~mm}$, to measure the axial profiles of the electron temperature, ion velocity distributions, and electric potential. 
where $\phi_{p}, \phi_{c f}, m, M$, and $k$ are the plasma potential, floating potential without the probe heating current, electron and Xe mass, and Boltzmann constant, respectively. The plasma potential $\phi_{p}$ is determined using the relation, $\phi_{p}=\phi_{h f}+\beta k T_{e} / e$, where $\phi_{h f}$ is the floating potential with the heating current, and $\beta$ was set as 1.5 assuming secondary emission current from the probe surface is larger than the incident current to the probe [28].

The line-of-sight integrated Xe I and Xe II spectra in the plume region were obtained using an optical fiber (Avantes, FC-UVIR600-2-ME) and a charge-coupled device (CCD) based-spectrometer (Ocean Optics, MAYA 2000), which provides a spectral resolution of $0.4 \mathrm{~nm}$. The emission spectra were obtained in an axial location of $10 \mathrm{~mm}$ from the exit plane, with a spatial resolution of $3.4 \mathrm{~mm}$. The ratio of the ionization rates in the plume region from the two discharge modes was calculated from the Xe I line intensity ratios.

The experiments were performed in a vacuum chamber with a length of $3.0 \mathrm{~m}$ and a diameter of $1.5 \mathrm{~m}$, which was equipped with two cryogenic pumps (ULVAC, U22HB). At a Xe mass flow rate of $0.49 \mathrm{mg} / \mathrm{s}$, the base pressure and operating pressure were maintained at $8 \times 10^{-7}$ torr and $7 \times 10^{-6}$ torr, respectively. A pendulum-type thruster stand was used for the thrust measurements [29].

\section{Experimental Results}

Stable operation of the thruster was achieved with a discharge current $\left(I_{d}\right)$ in the range $0.20-0.38 \mathrm{~A}$ and an anode voltage $\left(V_{a}\right)$ in the range $120-280 \mathrm{~V}$ at a Xe mass flow rate $(\dot{m})$ of $0.27-0.42 \mathrm{mg} / \mathrm{s}$. The corresponding anode power range was 33-73 W. Discharge became unstable below the anode power of approximately $33 \mathrm{~W}$. 
where $I_{i}, j(\theta)$, and $R$ are the total ion current, angular ion current density distribution, and the distance between the exit of the thruster and the surface of the Faraday probe, respectively.

As the discharge transitions from Mode A to Mode B, we found that both the ion and electron currents decreased. However, the decrease in the ion current (4\%) was much less significant than the decrease in the electron current (30\%), which results in a jump in the current utilization $\eta_{c}=I_{i} / I_{d}$ (by $12 \%$ ) (Fig. 4(c)). This is an encouraging result for the practical application of this class of thruster.

A significant difference was observed in the structure of the ion acceleration region between the two modes. The ion velocity distribution functions (IVDFs) were measured using LIF spectroscopy along the mid-channel line with an axial distance $z=0-52 \mathrm{~mm}$ from the exit plane $(z=0)$. The most probable ion speeds from the IVDFs versus $z$ are plotted in Fig. 5(a). For the sake of comparison, the measured ion speeds, obtained at different $V_{a}$ and normalized by $v_{a}=\sqrt{2 e V_{a} / M}$, where $e$ and $M$ are the electron charge and Xe mass, respectively, are also shown in Fig. 5(b). One immediate observation from the figures is that the majority of the ion acceleration occurs within only a few millimeters from the exit of the thruster in Mode B, which is similar to conventional annular Hall thrusters [30]. On the other hand, the structure of the acceleration region in Mode A is significantly different from that of Mode B, as it displays a gradual increase in the ion speed, up to several tens of millimeters from the exit of 
the thruster. This indicates that the ion acceleration region is significantly stretched out in the plasma plume region. It should be noted that the location of the ion energy corresponding to $75 \%$ of $v_{a}$ is $z=40 \mathrm{~mm}$, which is twice as long as the channel depth of this thruster.

Figure 5(c) depicts the profiles of the electrostatic potential of the two modes at $\dot{m}=0.42 \mathrm{mg} / \mathrm{s}$, as determined using both LIF and emissive probe diagnostics. The profile of the potential determined by the LIF measurement was calculated based on the conservation of kinetic energy of the Xe II ions, neglecting collisions. The results from both diagnostics are generally in good agreement, where the discrepancy seems to be due to the perturbation of the plasma caused by the emissive probe being present near the thruster exit. This figure clearly confirms the extended structure of the potential gradient outside of the exit of the thruster in Mode A. The electron temperatures in the plume region, obtained using the emissive probe, were in the ranges 4.3-5.4 eV and 3.7-6.6 eV in Mode A and Mode B, respectively (Fig. 5(d)); these are in a similar range as typical Hall thruster plasma plumes [31-33]. The electron temperature in Mode B was lower near the thruster within $40 \mathrm{~mm}$ of the exit.

The ion energy distribution functions (IEDFs), obtained at four different $V_{a}$ at $0.42 \mathrm{mg} / \mathrm{s}$, are depicted in Fig. 6(a). This figure shows the increases in the full width at half maximum (FWHM) in Mode A from 22 to $28 \mathrm{eV} \mathrm{(29 \% )}$ as $V_{a}$ was increased from $140 \mathrm{~V}$ to $160 \mathrm{~V}$. A larger increment of the FWHM $(56 \mathrm{eV})$ is observed at the transitional point (at $180 \mathrm{~V}$ ) between the two modes, which shows the increment of both low-energy and the high-energy ions with respect to the most probable energy. On the other hand, in Mode B, the FWHM was significantly lower and remains nearly constant $\left(38 \mathrm{eV}\right.$ ) even as $V_{a}$ was increased (Fig. 6(b)). These results suggest that the overlapped region between the ionization and the acceleration regions gradually increases with $V_{a}$ in Mode $\mathrm{A}$, while the extent of overlap saturates in Mode B regardless of $V_{a}$, as reported in Refs. [34-36]. For the sake of comparison, the IEDF from another group (blue) is also plotted in the figure [35].

In order to fully investigate the different features of the two discharge modes, the optical emission spectra of Xe I and Xe II were obtained axially at $z=10 \mathrm{~mm}$ and along the radial direction going through the mid channel line of the thruster, as illustrated in Figs. 7(c) and (d), where the dotted line represents the line of sight. The intensities of the Xe II, shown in Fig. 7(a), are significantly lower in Mode B (red), by approximately a factor of two, compared to those in Mode A (black). This suggests a large reduction in the population of the ion charge state which is related to each emission line. The ionization rates in the plasma plume region of the two modes were then compared using the line ratios of Xe I emission intensities, where the measured spectra are shown in Fig. 7(b). The ionization rate is expressed as

$$
\dot{n}_{i z}=n_{e} n_{n} k_{i z},
$$

where $n_{e}$ and $n_{n}$ are the electron and neutral particle densities, respectively. $k_{i z}$ is the electron-impact ionization rate coefficient averaged over the Maxwellian electron velocity distribution function [3,37,38], where the electron temperature at $z=10 \mathrm{~mm}$ from Fig. 5(d) was used. Here, the information about the ratios of $n_{e}$ and $n_{n}$ were obtained from the Xe I emission intensities as follows. The three prominent Xe I emission lines shown in Fig. 7 (b) are associated with the transitions from $5 p^{5} 6 p\left(p^{\prime}\right)$ (Paschen notation: $2 p_{i}$ ) to $5 p^{5} 6 s^{\prime}(1 / 2)_{1}$ or $5 p^{5} 6 s(3 / 2)_{1}$ (Paschen notation: $\left.1 \mathrm{~s}_{2}, 1 \mathrm{~s}_{4}\right)$, where the lower states $1 \mathrm{~s}_{2}$ and $1 \mathrm{~s}_{4}$ are optically coupled to the ground state. The contribution of the excitation out of the metastable state $\left(1 \mathrm{~s}_{5}\right)$ to the intensity of three Xe I spectra of $788.7 \mathrm{~nm}\left(2 \mathrm{p}_{1}-1 \mathrm{~s}_{2}\right), 828.0$ $\mathrm{nm}\left(2 \mathrm{p}_{5}-1 \mathrm{~s}_{4}\right)$, and $834.7 \mathrm{~nm}\left(2 \mathrm{p}_{3}-1 \mathrm{~s}_{2}\right)$ are negligible in a typical Hall thruster plasma, and thus, the emission intensity of these lines per unit volume can be approximated as [39]

$$
I_{\lambda}(X e I)=\frac{h c}{4 \pi \lambda} n_{e} n_{n}\left(k_{e 0}^{\lambda}+\alpha k_{1}^{\lambda}+\frac{1-\alpha}{2} k_{2}^{\lambda}\right),
$$


where $h$ is the Planck constant and $c$ is the speed of light. The charge-state parameter $\alpha$ is the ratio of the Xe II ion density to the electron density, which is typically within the range $0.70-0.95$ [39-41]. $k_{e 0}^{\lambda}$ is the rate coefficient for electron-impact excitation from the ground state, which is averaged over the Maxwellian electron velocity distribution function, and $k_{1}^{\lambda}$ and $k_{2}^{\lambda}$ are the rate coefficients for the Xe II and Xe III ion-impact excitation from the ground state, respectively. From Eq. (4), the ratio of the measured Xe I line intensities in the two modes is given as

$$
\frac{I_{\lambda, B}}{I_{\lambda, A}}=\left(\frac{n_{e, B}}{n_{e, A}}\right)\left(\frac{n_{n, B}}{n_{n, A}}\right)\left(\frac{k_{e 0, B}^{\lambda}+\alpha k_{1, B}^{\lambda}+(1-\alpha) k_{2, B}^{\lambda} / 2}{k_{e 0, A}^{\lambda}+\alpha k_{1, A}^{\lambda}+(1-\alpha) k_{2, A}^{\lambda} / 2}\right),
$$

where $\lambda$ are $788.7 \mathrm{~nm}, 828.0 \mathrm{~nm}$, and $834.7 \mathrm{~nm}$, respectively. Here, $\alpha$ was calculated using the measured multiply-charged ion current fractions. The normalized multiply-charged ion current fractions were $0.87,0.10$, and 0.03 for $\mathrm{Xe}^{+}, \mathrm{Xe}^{2+}$, and $\mathrm{Xe}^{3+}$ ions, respectively, at $160 \mathrm{~V}$ and $0.42 \mathrm{mg} / \mathrm{s}$ (Mode A), while the values showed no significant difference at $200 \mathrm{~V}$ and $0.42 \mathrm{mg} / \mathrm{s}$ (Mode B). The multiply-charged ion velocity $v_{Z+}$ is expressed as $v_{Z+}=\sqrt{2 Z e V_{a} / M}(Z=1,2,3)$ and thus $n_{Z+} \propto Z^{-3 / 2} I_{Z+}$, where $M, n_{Z+}$, and $I_{Z+}$ are the Xe mass, $\mathrm{Xe}^{Z+}$ ion density, and $\mathrm{Xe}^{Z+}$ ion current, respectively. Then, the charge-state parameter $\alpha=n_{1+} / n_{e}$ can be approximated as $\alpha \simeq n_{1+} / \Sigma_{Z=1,2,3} Z n_{Z+} \simeq I_{1+} / \Sigma_{Z=1,2,3} Z^{-1 / 2} I_{Z+} \approx 0.91$ assuming the quasi-neutrality of the plasma (i.e. $\left.n_{e} \simeq \Sigma_{Z=1,2,3} Z n_{Z+}\right)$. The line ratios from $\mathrm{Eq}(5)$ can be determined by the measured intensities, the excitation rate coefficients calculated using the cross sections from Ref. [42], and the measured electron temperature from Fig. $5(\mathrm{~d})$, where we obtain the relation $\left(n_{e, B} / n_{e, A}\right)\left(n_{n, B} / n_{n, A}\right)=0.98-1.17$. Therefore, the ratio of the ionization rates in the two modes can be calculated using Eq. (3) as

$$
\frac{\dot{n}_{i z, B}}{\dot{n}_{i z, A}}=\left(\frac{n_{e, B}}{n_{e, A}}\right)\left(\frac{n_{n, B}}{n_{n, A}}\right)\left(\frac{k_{i z, B}}{k_{i z, A}}\right)=(0.98-1.17)\left(\frac{k_{i z, B}}{k_{i z, A}}\right),
$$

Because $k_{i z, B} / k_{i z, A} \approx 0.60$ at $z=10 \mathrm{~mm}, \dot{n}_{i z, B} / \dot{n}_{i z, A}$ is in the range of $0.59-0.70$. This means that the ionization rate in the plume in Mode B is lower than that in Mode A, by approximately $30-41 \%$.

Similar variations were also observed in the propellant-induced mode change (i.e. the mode change from 0.32 $\mathrm{mg} / \mathrm{s}$ to $0.42 \mathrm{mg} / \mathrm{s}$ while holding the anode voltage constant at $200 \mathrm{~V}$ ). A significant narrowing of the beam angle from $69^{\circ}$ to $52^{\circ}$, as well as a $13 \%$ increase in the current utilization (from 0.59 to 0.66 ), was observed as the plasma transitions from Mode A $(200 \mathrm{~V}, 0.32 \mathrm{mg} / \mathrm{s})$ to Mode B $(200 \mathrm{~V}, 0.42 \mathrm{mg} / \mathrm{s})$. The reduction in the FWHM in the IEDFs and the localization of the acceleration region were also observed, as shown in Fig. 5 and Fig. 6, respectively. In particular, the ion acceleration region extended into the plume region in Mode A. Additionally, the reduction in the FWHM of the IEDF as the mode transitions at $200 \mathrm{~V}$ was $43 \%$. Therefore, the localization of the ion acceleration and the reduction in the beam angle due to the transition in the discharge from Mode A to Mode B were commonly observed regardless of the mode changes induced by increasing $\dot{m}$ or $V_{a}$.

\section{Discussion}

In the Hall thruster plasmas, the ionization of neutral particles actively takes place upstream inside the discharge channel and part of this region generally overlaps with the region where there is a large potential drop [43,44]. As a result, the IEDF shows a finite width, and the shape of the IEDF is determined by the structures of the ionization and acceleration regions. Our experimental results show distinguishable tendencies in the FWHM of the IEDFs in 
the two modes (Fig. 6(b)), which suggests different structures of the ionization and acceleration regions. Understanding of these structures is attempted using the schematic diagrams illustrated in Figs. 7 (c) and (d). The green area indicates the overlapping area between the two regions. Structures in the upstream region were not analyzed in this study due to the diagnostic accessibility limitations and thus the same in the diagram.

Mode A exhibited a consistent, axially extended structure of the acceleration region, regardless of the values of $V_{a}$ and $\dot{m}$ (Fig. 5(b)). The monotonic broadening of the IEDF as $V_{a}$ was increased in Mode A (Fig. 6(b)) indicates that the extent of overlap between the ionization and acceleration regions increases with $V_{a}$. In particular, both the lower and higher energy portions of the IEDF, with respect to the most probable energy, increase with $V_{a}$, as shown in Fig. 6(a). This indicates that the ionization region extends out in the upstream and also downstream directions, becoming increasingly overlapped with the acceleration region. Particularly in Mode A, active ionization occurs beyond the thruster exit, to a further extent than in Mode B. This point is inferred from higher ionization rate (by approximately 30-41\%) and Xe II emission intensities (by 48\%) in the plume region (Fig. 7(a)). This results in the ball-shaped plume, as shown in Fig 2(a).

On the other hand, in Mode B, the majority of the ion acceleration is localized within $10 \mathrm{~mm}$ from the exit (Fig. 5(b)), and therefore a lower amount of ionization is expected in the plume than in Mode A. This was confirmed by the lower ionization rate as well as the lower Xe II emissions in the plume region. The saturation of the FWHM of the IEDF with $V_{a}$ indicates that the ionization region becomes no longer broadened axially in this mode. This suggests that both the acceleration and ionization are localized near the exit plane in Mode B, as illustrated in Fig. $7(d)$.

The differences in the structure of the ionization regions in the two modes are related to the properties of the plasma and the thruster performance. In Mode A, the low-velocity Xe II ions, generated in the downstream ionization region, can gradually accelerate through the plume region, particularly along a direction perpendicular to the diverging magnetic field lines (Fig. 1). This can lead to a large beam angle within this operational regime. On the other hand, in Mode B, the electron current is smaller, which results in an increase in the current utilization (Fig. 4(c)). This suggests that the electron cross-field transport inside the channel is lower in Mode B than in Mode A, which possibly affects the localization of the ionization. The total ionization rate decreased from Mode A to Mode $\mathrm{B}$ (from $160 \mathrm{~V}$ to $200 \mathrm{~V}$ at $0.42 \mathrm{mg} / \mathrm{s}$ ), which was followed by a decrease in the ion current, even while $V_{a}$ was increased while holding $\dot{m}$ constant. However, the thruster performance still increased due to the increased electron confinement along the magnetic field as well as the significant ion acceleration along the converging direction at the exit plane, which leads to less divergence of the ion beam.

We believe the mode change observed in this study is related to the large magnetic field strength near the inner pole surface, which is represented at the bottom of Fig. 1. The magnetic field intensity in this region reaches 1.0$1.4 \mathrm{kG}$ near the surface, which is 3-4 times larger than that of a typical $\mathrm{kW}$-class Hall thruster [45]. This strong magnetic field can reduce the cross-field mobility $\left(\mu_{\perp}\right)$ of the electrons emitted from the cathode and prevent them from diffusing into the discharge channel. These electrons can then participate in the ionization and excitation of neutral particles within this region, which results in a large ionization rate beyond the exit plane, as well as the ballshaped light emission adjacent to the inner pole surface in Mode A, as shown in Fig. 2(b).

The cross-field electron flux is given by $\boldsymbol{\Gamma}_{\mathrm{e}}=n_{\mathrm{e}} \mathbf{v}_{\mathrm{e}, \perp} \simeq n_{\mathrm{e}} \mu_{\perp} \mathbf{E} \propto n_{\mathrm{e}} v_{\mathrm{en}} \mathbf{E} / \mathrm{B}^{2}$, where $n_{\mathrm{e}}, \mathbf{v}_{\mathrm{e}, \perp}, v_{\mathrm{en}}, \mathbf{E}$, and $\mathrm{B}$ are the electron density, electron cross-field velocity, effective collision frequency, electric field, and magnetic field strength, respectively. Therefore, the augmentation of the electron flux toward the discharge channel can be facilitated by either increasing the electron-neutral collision frequency or electric field strength in this region. This is in agreement with our experimental observation, where increasing $\dot{m}$ or $V_{a}$ induced the change from Mode A to Mode B. 


\section{Conclusion}

Two distinct discharge modes, with significantly different structures of ionization and acceleration regions were observed in a 50-W-class Hall thruster plasma. The thruster exhibited ball-shaped plasma (Mode A) with the acceleration and ionization regions extending beyond the thruster exit in a broad range of operational conditions. On the other hand, by increasing either the mass flow rate with a fixed anode voltage $(>200 \mathrm{~V})$ or the anode voltage with a fixed mass flow rate $(>0.37 \mathrm{mg} / \mathrm{s})$, the plasma transitions to a different discharge mode with a narrower and more extended plume (Mode B), resulting in improved thruster performance. We speculate that this mode change is due to the large magnetic field strength around the outer surface of the inner pole, which causes the difference in the electron cross-field transport towards the discharge channel. In practical applications of these types of lowpower Hall thrusters, Mode B is considered to be more suitable than Mode A.

\section{Acknowledgements}

This work was partially supported by the Space Core Technology Program (Grant No. 2014M1A3A3A02034510) via the National Research Foundation of Korea, funded by the Ministry of Science and ICT, Republic of Korea.

\section{References}

[1] Goebel D M and Katz I 2008 Fundamentals of Electric Propulsion: Ion and Hall Thrusters (John Wiley \& Sons)

[2] Boeuf J P 2017 Tutorial: Physics and modeling of Hall thrusters J. Appl. Phys. 121011101

[3] Lev D, Myers R M, Lemmer K M, Kolbeck J, Koizumi H and Polzin K 2017 The technological and commercial expansion of electric propulsion in the past 24 years 35th Int. Electric Propulsion Conf. (Atlanta, GA) IEPC-2017-242

[4] Mazouffre S 2016 Electric propulsion for satellites and spacecraft: Established technologies and novel approaches Plasma Sources Sci. Technol. 25033002

[5] Levchenko I, Bazaka K, Ding Y, Raitses Y, Mazouffre S, Henning T, Klar P J, Shinohara S, Schein J, Garrigues L, Kim M, Lev D, Taccogna F, Boswell R W, Charles C, Koizumi H, Shen Y, Scharlemann C, Keidar M and Xu S 2018 Space micropropulsion systems for cubesats and small satellites: From proximate targets to furthermost frontiers Appl. Phys. Rev. 5011104

[6] Conversano R W, Angeles L, Goebel D M, Hofer R R, Mikellides I G, Katz I and Wirz R E 2015 Magnetically shielded miniature Hall thruster: Design improvement and performance analysis 34th Int. Electric Propulsion Conf. (Kobe, Japan) IEPC-2015-100

[7] Loyan A V, Maksymenko T A 2007 Performance investigation of SPT-20M low power Hall effect thruster 30th Int. Electric Propulsion Conf. (Florence, Italy) IEPC-2007-100

[8] Szabo J, Tedrake R, Metivier E, Paintal S and Taillefer Z 2017 Characterization of a one hundred watt, long lifetime Hall effect thruster for small spacecraft 53rd AIAA/SAE/ASEE Jt. Propuls. Conf. (Atlanta, GA) AIAA-2017-4728

[9] Gurciullo A, Jarrige J, Lascombes P and Packan D 2019 Experimental performance and plume characterisation of a miniaturised 50W Hall thruster 36th Int. Electric Propulsion Conf. (Vienna, Austria) 
[10] Mazouffre S and Grimaud L 2018 Characteristics and performances of a 100-W Hall thruster for microspacecraft IEEE Trans. Plasma Sci. 46 330-7

[11] Ikeda T, Togawa K, Nishida T, Tahara H and Watanabe Y 2011 Research and development of very low power cylindrical Hall thrusters for nano-satellites 32nd Int. Electric Propulsion Conf. (Wiesbaden, Germany) IEPC-2011-039

[12] Ito T, Gascon N, Crawford W S and Cappelli M A 2007 Experimental characterization of a micro-Hall thruster J. Propul. Power 23 1068-74

[13] Smirnov A, Raitses Y and Fisch N J 2002 Parametric investigation of miniaturized cylindrical and annular Hall thrusters J. Appl. Phys. 92 5673-9

[14] Conversano R W, Goebel D M, Hofer R R, Matlock T S and Wirz R E 2015 Development and initial testing of a magnetically shielded miniature Hall thruster IEEE Trans. Plasma Sci. 43 103-17

[15] Guerrini G, Michaut C, Dudeck M and Bacal M 1997 Parameter analysis of three small ion thrusters (SPT20, SPT-50, A3) 2nd European Spacecraft Propulsion Conference, ESA SP-398-441

[16] Belikov M B, Gorshkov O A, Dyshlyuk E N, Lovtzov A S and Shagayda A A 2007 Development of lowpower Hall thruster with lifetime up to 3000 hours 30th Int. Electric Propulsion Conf. (Florence, Italy) IEPC2007-129

[17] Yim J T 2008 Computational modeling of Hall thruster channel wall erosion PhD Thesis University of Michigan, Ann Arbor

[18] Misuri T and Andrenucci M 2008 HET scaling methodology: Improvement and assessment 44th AIAA/ASME/SAE/ASEE Jt. Propuls. Conf. Exhib. (Hartford, CT) AIAA-2008-4806

[19] Lee D, Kim H, Lee S, Doh G and Choe W 2019 Development and performance test of a 50 W-class Hall thruster 36th Int. Electric Propulsion Conf. (Vienna, Austria) IEPC-2019-599

[20] Kim H, Lim Y, Choe W, Park S and Seon J 2015 Effect of magnetic field configuration on the multiply charged ion and plume characteristics in Hall thruster plasmas Appl. Phys. Lett. 106154103

[21] Kim H, Lim Y, Choe W and Seon J 2014 Effect of multiply charged ions on the performance and beam characteristics in annular and cylindrical type Hall thruster plasmas Appl. Phys. Lett. 105144104

[22] Kim H, Choe W, Lim Y, Lee S and Park S 2017 Magnetic field configurations on thruster performance in accordance with ion beam characteristics in cylindrical Hall thruster plasmas Appl. Phys. Lett. 110114101

[23] Brown D L 2017 Recommended practice for use of Faraday probes in electric propulsion testing J. Propul. Power 33 614-37

[24] Doh G, Kim H, Lee D, Park S, Choe W and Yoon S 2019 Significant acceleration of Xe II ions outside discharge channel 36th Int. Electric Propulsion Conf. (Vienna, Austria) IEPC-2019-252

[25] Sheehan J P, Raitses Y, Hershkowitz N and McDonald M 2016 Recommended practice for use of emissive probes in electric propulsion testing J. Propul. Power 33 614-37

[26] Sheehan J P and Hershkowitz N 2011 Emissive probes Plasma Sources Sci. Technol. 20063001

[27] Smirnov A, Raitses Y and Fisch N J 2004 Plasma measurements in a $100 \mathrm{~W}$ cylindrical Hall thruster J. Appl. Phys. 95 2283-92

[28] Schwager L A 1993 Effects of secondary and thermionic electron emission on the collector and source sheaths of a finite ion temperature plasma using kinetic theory and numerical simulation Phys. Fluids B 5 $631-45$

[29] Lee S, Kim H and Choe W 2019 Tailoring of magnetic field for performance improvement in a small Hall thruster plasma IEEE Trans. Plasma Sci. 47 4670-6

[30] Mazouffre S 2013 Laser-induced fluorescence diagnostics of the cross-field discharge of Hall thrusters Plasma Sources Sci. Technol. 22013001

[31] Conversano R W 2015 Low-power magnetically shielded Hall thrusters PhD Thesis University of California, 
Los Angeles

[32] Mikellides I G, Katz I, Hofer R R, Goebel D M, de Grys K and Mathers A 2011 Magnetic shielding of the channel walls in a Hall plasma accelerator Phys. Plasmas 18033501

[33] Nakles M R, Brieda L, Reed G D, Hargus W A Jr and Spicer R L 2007 Experimental and numerical examination of the BHT-200 Hall thruster plume 43rd AIAA/ASME/SAE/ASEE Jt. Propuls. Conf. Exhib. (Cincinnati, OH) AIAA-2007-5305

[34] Hofer R R, Haas J M and Gallimore A D 2003 Ion voltage diagnostics in the far-field plume of a highspecific impulse Hall thruster 39th AIAA/ASME/SAE/ASEE Jt. Propuls. Conf. Exhib. (Huntsville, AL) AIAA2003-4556

[35] Conversano R W, Goebel D M, Hofer R R, Mikellides I G and Wirz R E 2017 Performance analysis of a low-power magnetically shielded Hall thruster: Experiments J. Propul. Power 33 975-83

[36] Brown D L 2009 Investigation of low discharge voltage Hall thruster characteristics and evaluation of loss mechanisms $P h D$ Thesis University of Michigan, Ann Arbor

[37] Mikellides I G, Katz I, Mandell M and Snyder J S 2001 A 1-D model of the Hall-effect thruster with an exhaust region 37th AIAA/ASME/SAE/ASEE Jt. Propuls. Conf. Exhib. (Salt Lake City, UT) AIAA-2001-3505

[38] Hayashi M 1983 Determination of electron-xenon total excitation cross sections, from threshold to $100 \mathrm{eV}$, from experimental values of Townsend's $\alpha$ J. Phys. D. Appl. Phys. 16 581-9

[39] Karabadzhak G F, Chiu Y and Dressler R A 2006 Passive optical diagnostic of Xe propelled Hall thrusters. II. Collisional-radiative model J. Appl. Phys. 99113305

[40] Gulczinski III F S, Hofer R R and Gallimore A D 1999 Near-field ion energy and species measurements of a $5 \mathrm{~kW}$ laboratory Hall thruster 35th AIAA/ASME/SAE/ASEE Jt. Propuls. Conf. Exhib. (Los Angeles, CA) AIAA-99-2430

[41] Manzella D H 1993 Stationary plasma thruster plume emissions 23rd AIAA/AIDAA/DGLR/JSASS Int. Electric Propulsion Conf. (Seattle, WA) IEPC-1993-097

[42] Chiu Y, Austin B L, Williams S, Dressler R A and Karabadzhak G F 2006 Passive optical diagnostic of Xepropelled Hall thrusters. I. Emission cross sections J. Appl. Phys. 99113304

[43] Reid B M 2009 The influence of neutral flow rate in the operation of Hall thrusters $P h D$ Thesis University of Michigan, Ann Arbor

[44] Linnell J A and Gallimore A D 2006 Internal plasma potential measurements of a Hall thruster using plasma lens focusing Phys. Plasmas 13103504

[45] Pérez-Grande D, Fajardo P and Ahedo E 2015 Evaluation of erosion reduction mechanisms in Hall effect thrusters 34th Int. Electric Propulsion Conf. (Kobe, Japan) IEPC-2015-280 


\section{Figure captions}

Figure 1. Schematic of the Hall thruster used in the study and its magnetic field lines

Figure 2. (a) Discharge current versus anode voltage at four different Xe mass flow rates. The shaded area indicates 99\% confidence interval and the red arrows indicate the point where the discharge shows a mode change from Mode A to Mode B. (b) Photographs of the two plume modes where the pictures were taken at 0.32 $\mathrm{mg} / \mathrm{s}, 200 \mathrm{~V}$ for Mode A and $0.42 \mathrm{mg} / \mathrm{s}, 200 \mathrm{~V}$ for Mode B.

Figure 3 (a) Thrust, (b) anode efficiency, and (c) specific impulse plotted versus anode power at $0.32 \mathrm{mg} / \mathrm{s}$ (black) and $0.42 \mathrm{mg} / \mathrm{s}$ (red). The $99 \%$ confidence intervals are marked by the shaded area. The red arrows indicate the onset of the mode change $(0.42 \mathrm{mg} / \mathrm{s}, 160 \mathrm{~V})$.

Figure 4. (a) Angular profile of the ion current density at the two modes (Mode A at $160 \mathrm{~V}$ and Mode B at $200 \mathrm{~V}$; both at $0.42 \mathrm{mg} / \mathrm{s}$ ), (b) plume angle containing $95 \%$ of the ion current, and (c) current utilization $\left(I_{i} / I_{d}\right)$ versus anode power at $0.32 \mathrm{mg} / \mathrm{s}$ (black) and $0.42 \mathrm{mg} / \mathrm{s}$ (red). The red arrows indicate the onset of the mode change $(0.42 \mathrm{mg} / \mathrm{s}, 160 \mathrm{~V})$.

Figure 5. Axial profiles of the (a) most probable ion speed from the ion energy distribution function and (b) normalized ion speed in both modes. The blue curve in (a) and (b), obtained at $0.32 \mathrm{mg} / \mathrm{s}$ and $200 \mathrm{~V}$, also corresponds to Mode A, where the typical error of the measurement is shown at $z=0$. Axial profiles of the (c) electric potential and (d) electron temperature in Mode A (black) and Mode B (red). The 99\% confidence intervals are marked by the shaded area. The Mode A and Mode B were obtained at $160 \mathrm{~V}$ and $200 \mathrm{~V}$, respectively, at $0.42 \mathrm{mg} / \mathrm{s}$.

Figure 6. (a) Normalized ion energy distribution functions subtracted by their peak ion energies at $V_{a}=140 \mathrm{~V}$ and $160 \mathrm{~V}$ in Mode $\mathrm{A}$, at $180 \mathrm{~V}$ that corresponds to the transition point between the two modes, and at $200 \mathrm{~V}$ in Mode B. The mass flow rate $\dot{m}$ was fixed at $0.42 \mathrm{mg} / \mathrm{s}$ and the measurement point was at $z=265$ mm. (b) The full width at half maximum of the ion energy distribution functions for the two modes. For comparison, the IEDF from another group (blue) is also plotted [35].

Figure 7. Spectral intensities of (a) Xe II and (b) Xe I, integrated along the radial direction at $10 \mathrm{~mm}$ from the thruster exit plane. The spectra from Mode A $(160 \mathrm{~V})$ and Mode B $(200 \mathrm{~V})$ are denoted by black and red color, respectively, at fixed $\dot{m}=0.42 \mathrm{mg} / \mathrm{s}$. A schematic diagram (top view of the thruster) illustrating the ionization and acceleration structures in (c) Mode A and (d) Mode B. 


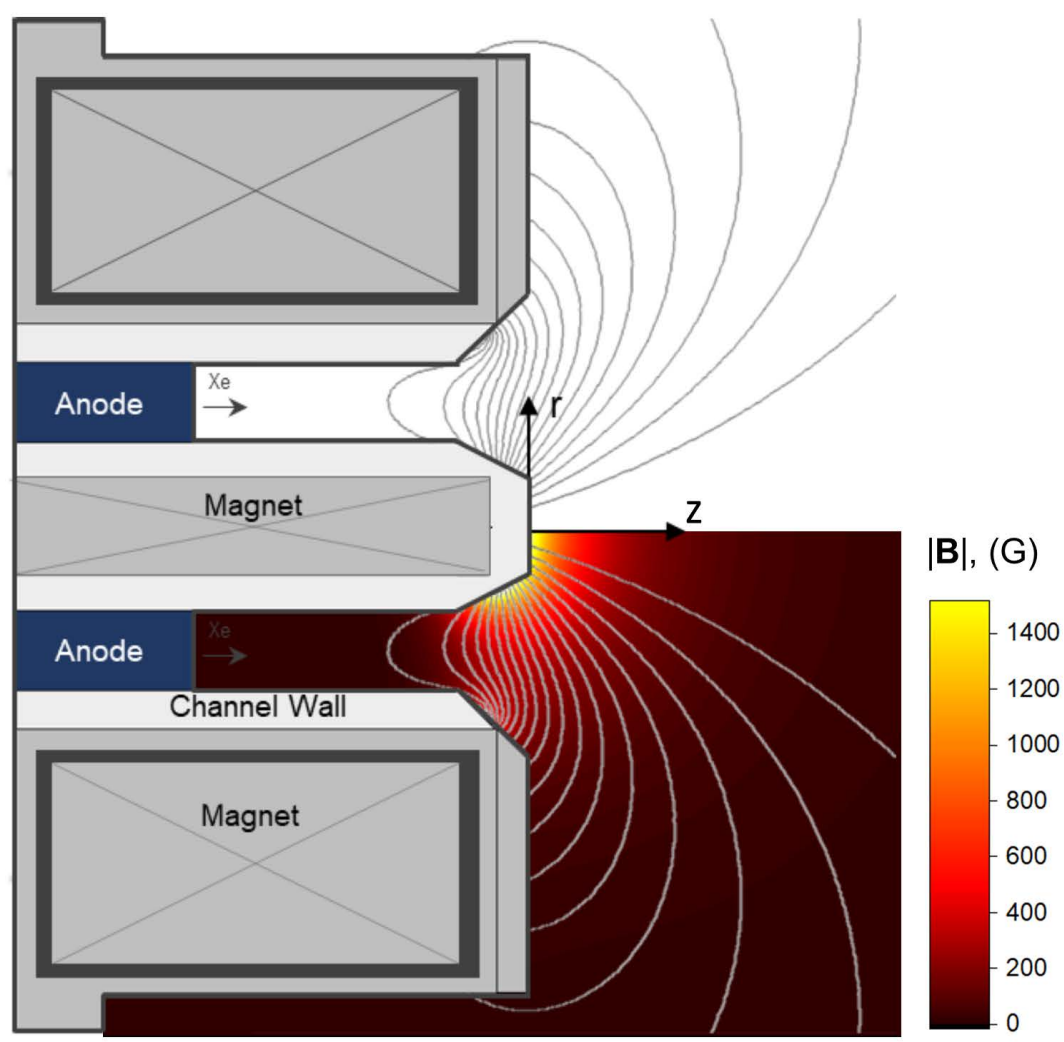

Figure 1. Lee et al. 
(a)

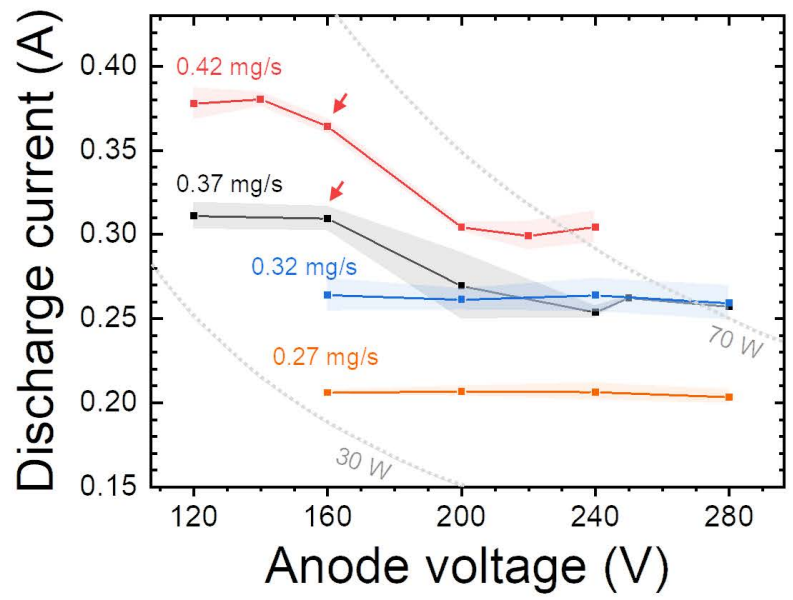

(b)

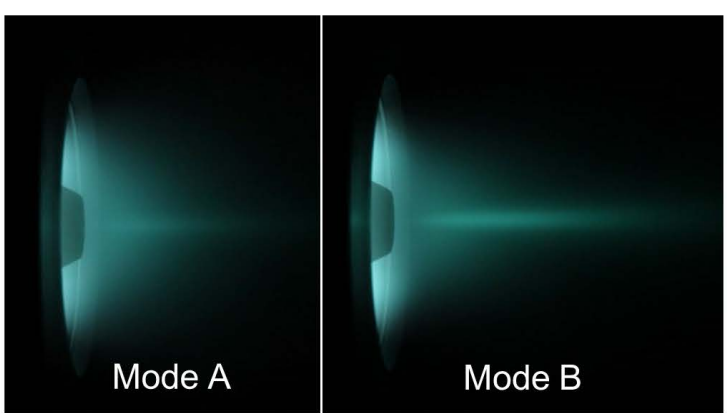

Figure 2. Lee et al. 

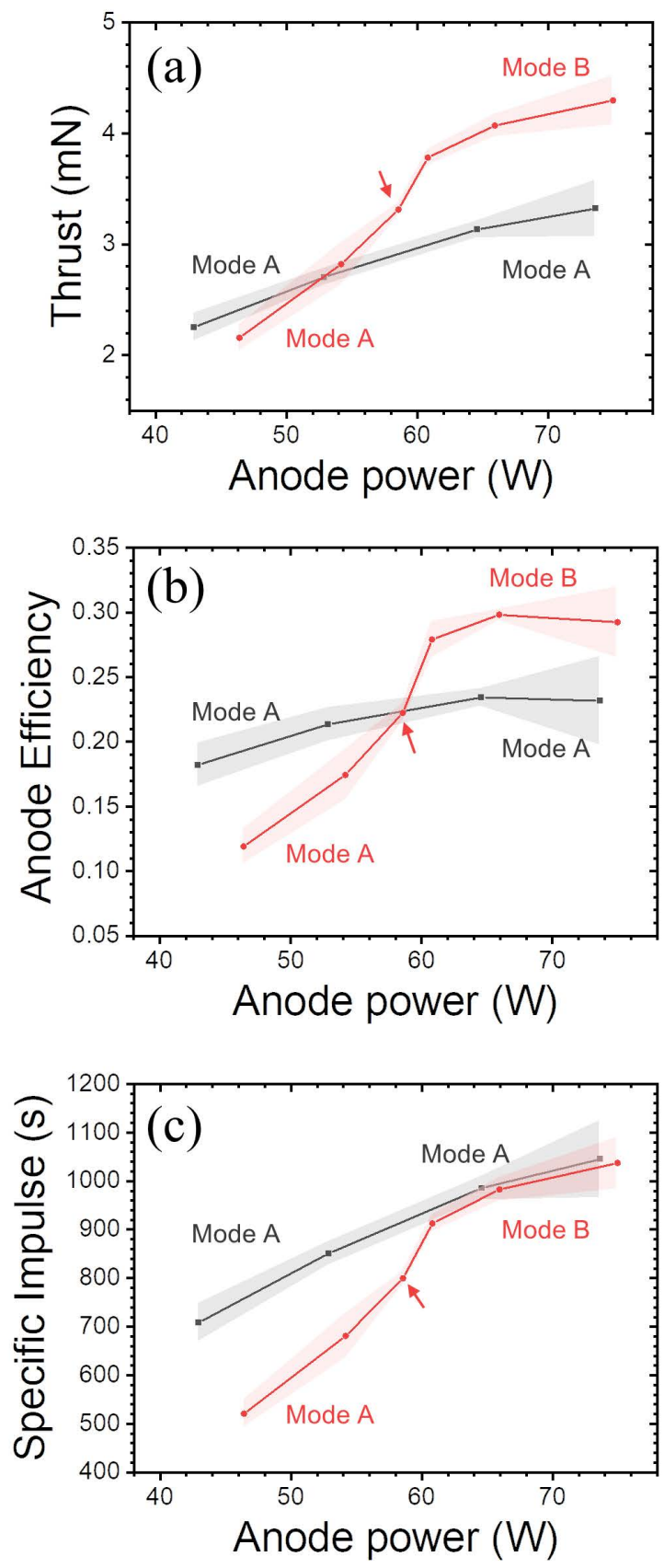

Figure 3. Lee et al. 

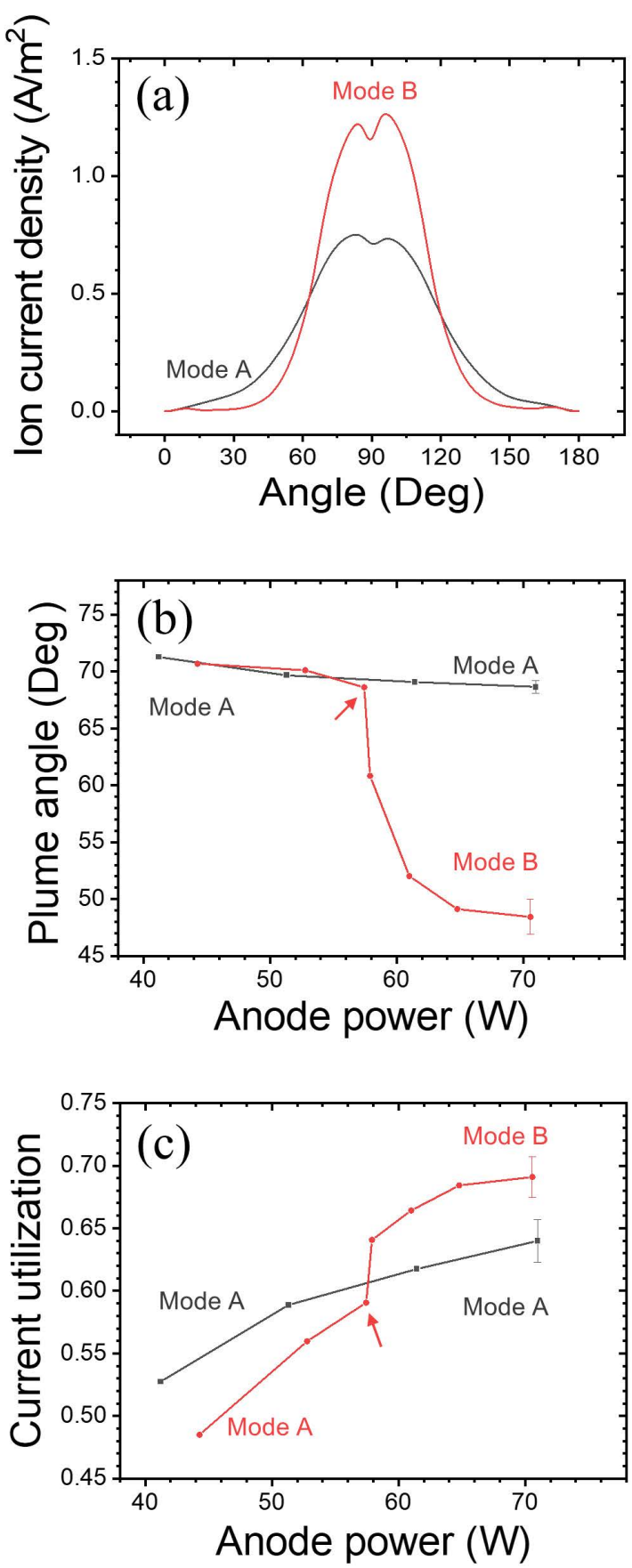

Figure 4. Lee et al. 

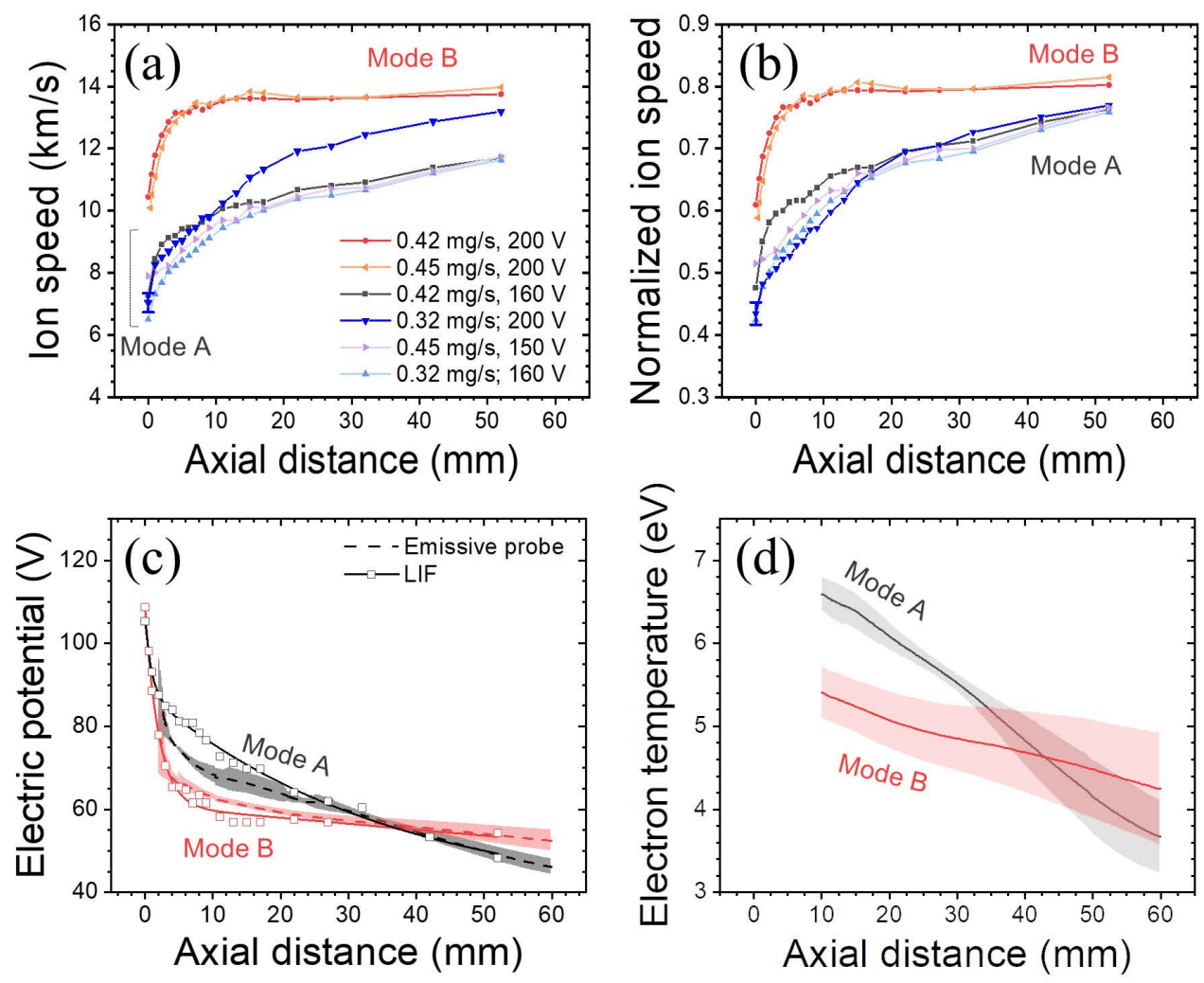

Figure 5. Lee et al. 

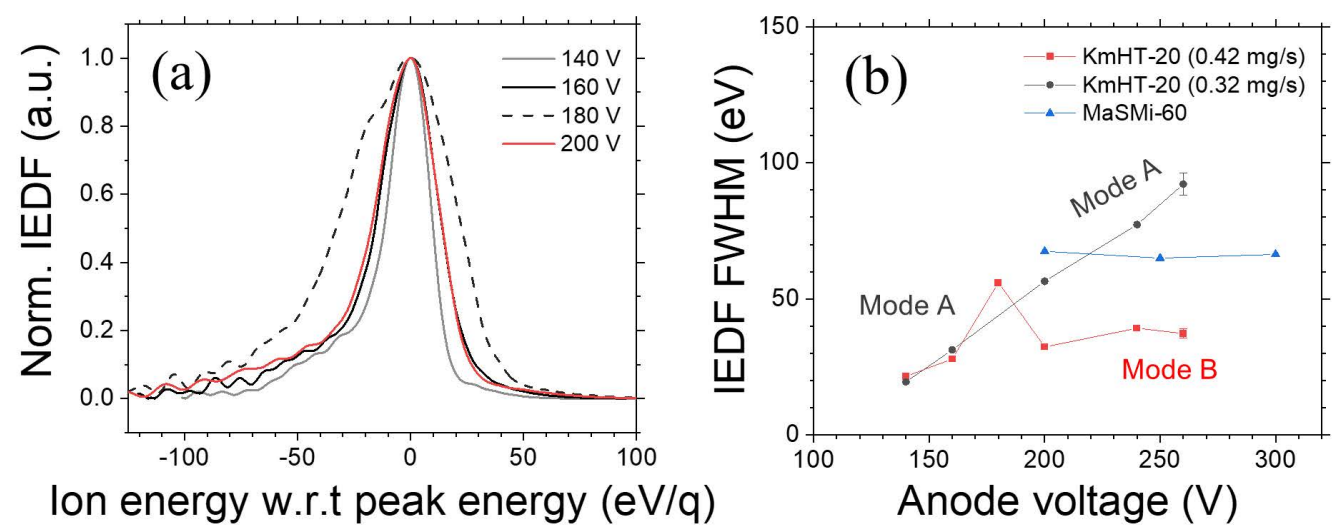

Figure 6. Lee et al. 

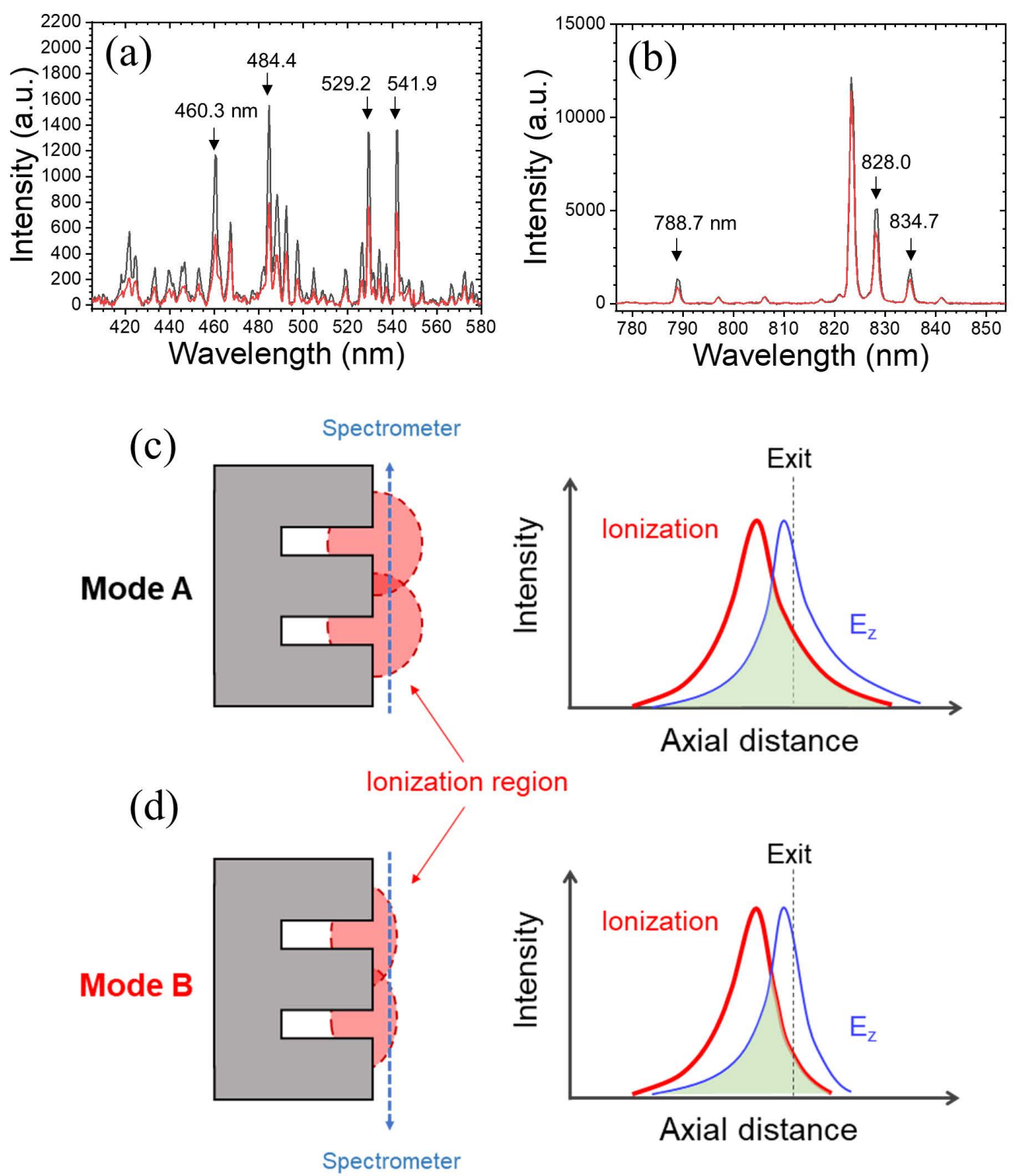

Figure 7. Lee et al. 